العدد الحادي والأربعون

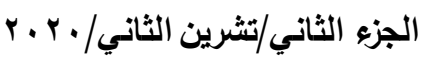

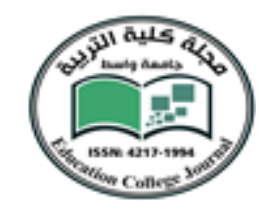

أثر تغير خصائص التيار النفاث شبه المداري وانعكاسها على أمطار العلق

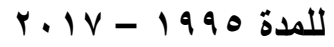

م.د. عبد العباس عواد لقته

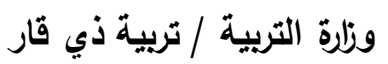

\title{
E-mail :abbasalwaily99@gmail.com
}

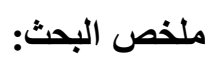

أكدت الدراسات لعدد كبير من الباحثبن والمنظمات الدولية ومنها الهيئة الحكومية المعنية

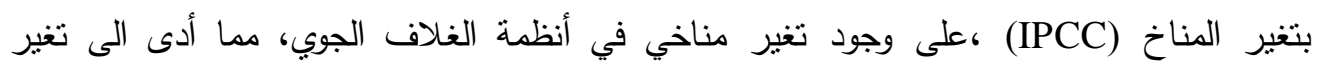

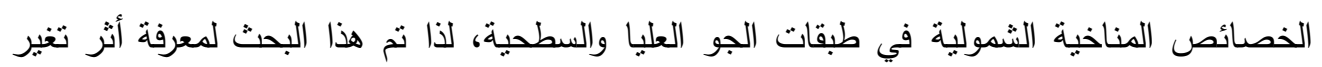
خصائص التيار النفاث شبه المداري فوق العراق وانعكاسه على المنظومات الجوية السطحية المسبية

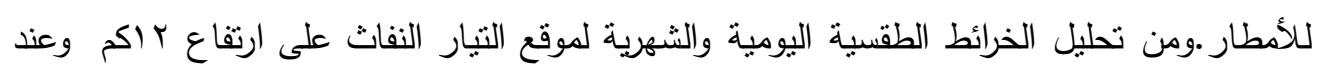

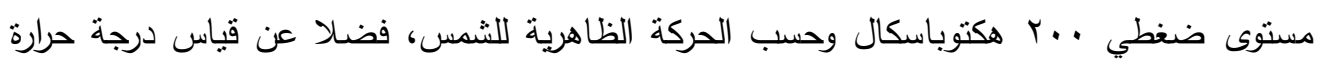

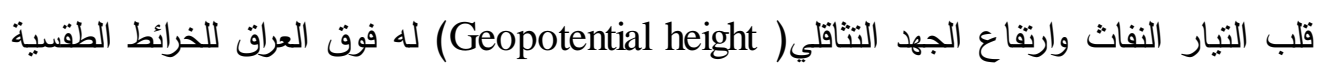

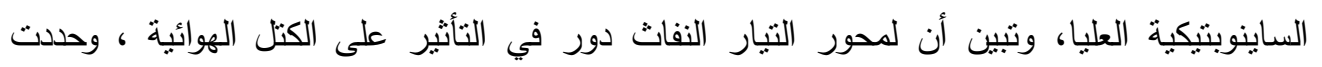


عكسية على المستوى الشهري والسنوي فوق العراق.

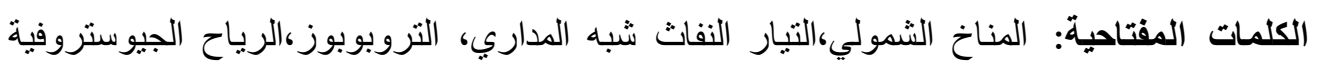

\section{Summary:}

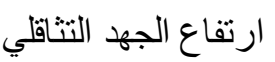

Previous studies by many researchers and international organizations ، including the Intergovernmental Panel on Climate Change (IPCC), have confirmed climate change in atmospheric systems, leading to a change in total climatic characteristics in the upper and surface atmosphere. This study was carried out to investigate the effect the changing characteristics of the Sub Tropical jet stream over Iraq and its reflection on the surface rain-based meteorological systems The analysis of the daily and monthly ritual maps of the site of the jet stream at a height of $12 \mathrm{~km}$, at a level of $200 \mathrm{hpa}$ and according to the movement of the sun, as well as measuring the temperature 
العدد الحادي والأربعون

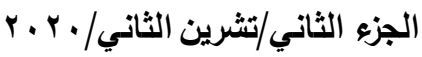

of the heart of the jet stream and Geopotential height over Iraq for top Synoptic maps، It was found that the axis of the jet stream had a role in influencing the air masses. The relation between the atmospheric pressure values was determined at $200 \mathrm{hpa}$ and the amount of rain. where the relationship was inverse at the monthly and annual level over Iraq.

المقدمة:

أكد التقرير التجميعي للأمم المتحدة أن التأثنر البشري على النظام المناخي واضح وآخذ في

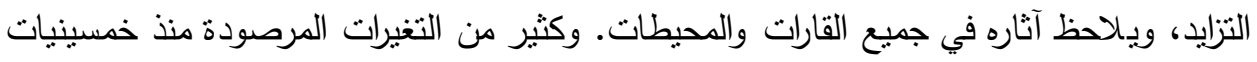
القرن العشرين لم يسبق لها مثيل على مدى مدة تتزاوح من عقود إلى آلاف السنين. والهيئة الحكومية

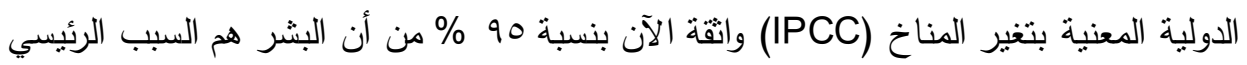

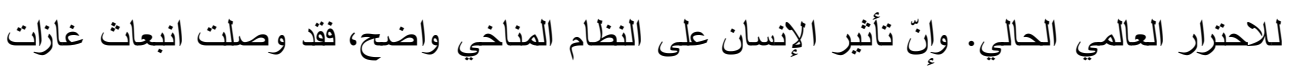
الاحتباس الحراري البشرية المنشأ الأخيرة عند أعلى قيمة تاريخية لها. وكانت لتغيرات لتفيرات المناخ الأخيرة آثنار واسعة النطاق النطاق على النظم البشرية والطبيعية. واحترار النظام المناخي واضح لا لبس فيه، والكثير من

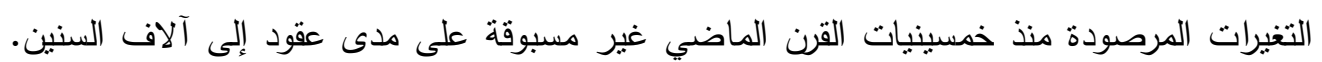

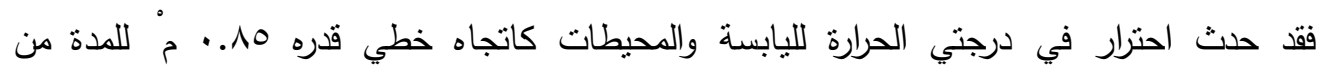

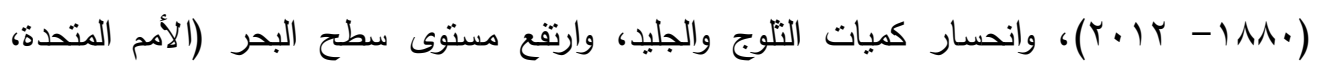

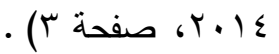

تمتل التيارات النفاثة (Jet Streams) أحدى أهم العوامل المؤثرة لنقل الطاقة الحرارية في نصفي الغلاف الجوي، إذ ان التيارات النفاثة في كلا النصفين يقعان مباشرة تحت طبقة التروبوبوز ، ولانلان

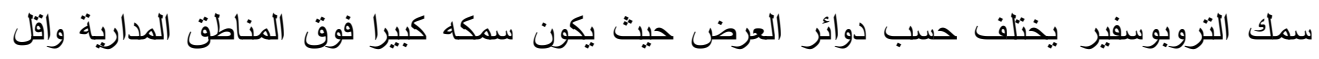

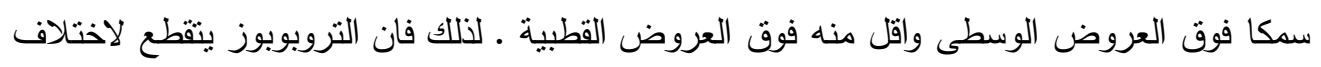

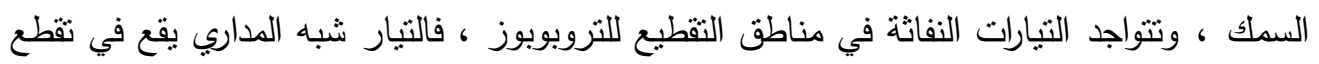

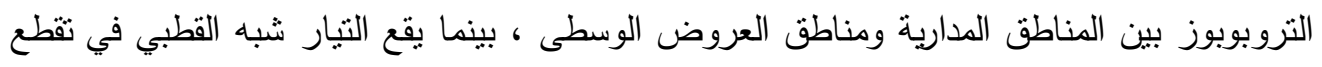

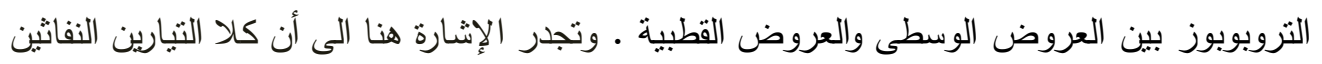

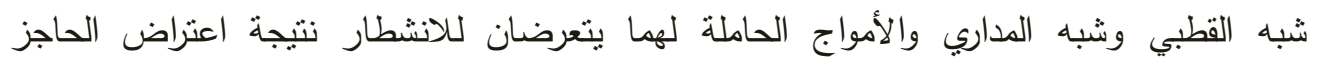

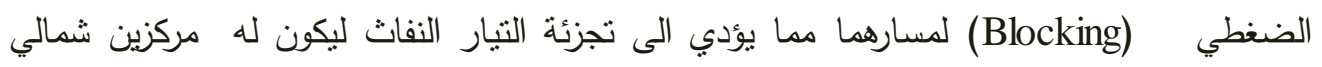


العدد الحادي والأربعون

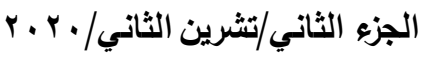

وجنوبي ، الا أن هذا الانشطار يؤدي الى إضعاف قوتهما وسرعتهما، لكنهما بلتقيان بعد مدة فيندمجان بخصائص جديدة مختلفة عن التيار الأصلي، وهذه الحالة تتكرر بصورة اكبر مع التيار النفاث شبه القطبي بسبب طبيعة الثقاء الكتل الهوائية القطبية والمدارية وسبب الحركة الدوامية الثديدة التي تحدثها على عكس التيار النفاث شبه المداري الذي يمناز بالاستقرارية كونه محمول على نطاق الضغط العالي شبه المداري وهذه الحالة تتكرر في الفصل البارد بصورة أكبر لبروز حالة التضاد



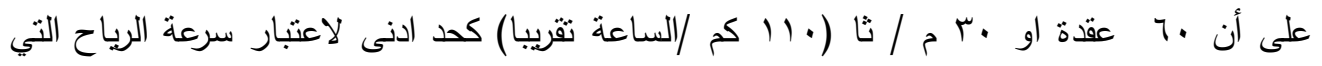
تمنل تياراً نفاثاً .

أما حركتها فهي تميل إلى اتخاذ مسارات حلزونية متعرجة، تقترب تارة من النطاق الاستوائي،

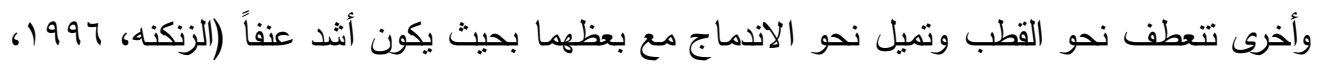

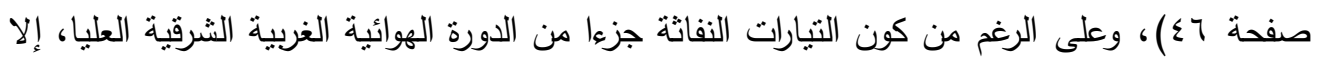
انه لوحظ اندفاع شديدة السرعة قوية تتحرك شمالا وجنوبا في مسارات عمودية على اتجاه حركتها، وترتكز على امتذاد محور شبه افقي في التروبوبوز العلوي أسفل الستراتوسفير، يحدد من خلال وجود قصي للهواء الافقي والعمودي الثديدين (الزنكنه، 997 1، صفحة rع). من ثم يحثث التبادل بين القطبين والمنطقة المدارية بالمستويات العليا من الغلاف الجوي. لذا تعد دراسة التيارات النفاثة من الدراسات الشمولية للمنظومات الضغطية العليا الساينوبتيكية والتي لها دور في حركة المنظومات الجوية التي تحتها ، والتيار النفاث شبه المداري هو احد التيارات النفاثة الرئيسة التي تساهم في حفظ النوازن الحراري مع التيار النفاث شبه القطبي في الغلاف الجوي فهي رياح عليا على شكل أحزمة من الهواء شديد السرعة تظهر في طبقات الجو العليا بالقرب من طبقة التروبوبوز على ارتفاع rا كم للتيار النفاث شبه المداري و وكم للتبار النفاث شبه القطبي وتتحرك فيه الرياح بسرعة كبيرة جدا من الغرب الى الثرق في كلا التيارين بحركة موجية جانبية

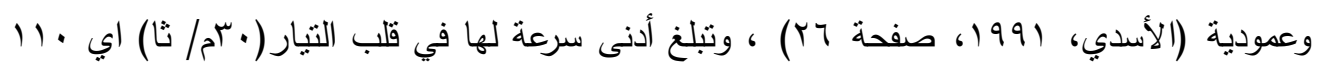

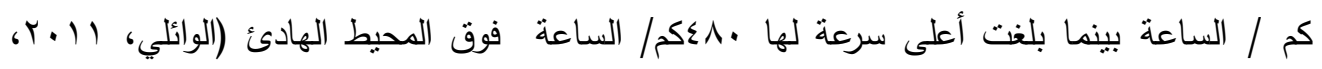

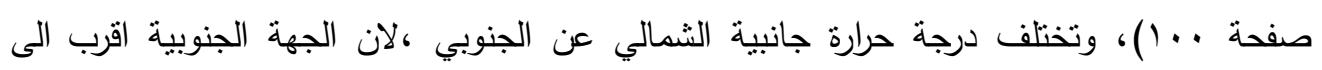
المنطقة المدارية وتكون أعلى حرارة من الجهة الشمالية التي تكون اقرب الى المنطقة القطبية ، ويشكل التيار النفاث نواة محورية لتدفق الهواء في طبقات الجو العليا وذلك بسبب التذرج الحراري الطولي الثديد بين العروض العليا والدنيا.يتراوح طوله آلاف الكيلومترات وعرضه مئات الكيلو مترات، 
العدد الحادي والأربعون

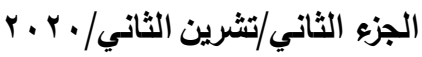

ويلعب التيار النفاث دور الموجه والمحرك للمنظومات التي تحته مثل الأمواج الهوائية والمرتفعات الجوية والمنخفضات الجوية (الأسدي، (991،، صفحة بr)، ويمتاز التيار النفاث بوجود ظاهرة القص الريحي (Wind Shear) الناتجة عن اختلاف سرعة الهواء عند أطرافه ،لانعدام الاحتكاك، وعندما يحدث تتاقص في سرعة الهواء (غرب الاخدود) أو شمال المحور الرئيسي للتيار النفاث يحدث قصاً هوائياً إعصاريا عند جنوب المدخل وشمال مخرج التيار النفاث (شرق الاخدود) وهذا يؤدي الى حدوث حالة عدم الاسنقرار الجوي المنمثل في نشوء المنخفض الجوي الجبهوي وتنشيط حالة التصعيد. وفي حالة تتاقص سرعة الرياح باتجاه غرب الأخدود من المحور الرئيسي (شرق الانبعاج) ينكون المرتفع الجوي وبالتالي سيادة الاستقرار الجوي

(الراوي و البياتي، • 99 (1، صفحة بـ ()).

مشكلة البحث: تكمن مشكلة البحث بما يأتي: 1- هل أن تباين ارتفاع وانخفاض الحركة الموجية للتيار النفاث شبه المداري وتغير درجة حرارة المستوى الذي يتحرك فيه أثّر في تغير حركة المنظومات الجوية السطحية ومنها التيار النفاث شبه المداري. r- ما مدى تغير ارتفاع المستوى الضغطي العلوي للتيار النفاث شبه المداري في التغير وتأثير ذلك على نوع المنظومات التي تحته. r- ما هي علاقة الارنباط بين ارتقاع مستوى الجهد الضغطي للتيار وكمية الأمطار الساقطة فوق العراق.

\section{فرضية البحث: في ضوء ما تقدم يمكن افتراض ما يأتي:}

ا - أن لتغير المناخ أثز في تغير خصائص التيار النفاث وتغير حركته الموجية العمودية والأفقية. r- ان تغير المنظومات العليا بما فيها التيار النفاث شبه المداري اثر على تغير المنظومات السطحية ومنها المنخفضات الجوية المسببة للتساقط فوق العراق. هدف البحث: يهدف البحث الى:

ا - التحليل الساينوبتيكي للخرائط الجوية الطقسية العليا عند مستوى ... هكتوباسكال. r- تحديد العلاقة بين قيم الضغط الجوي عند مستوى . . . هكتوباسكال (خطوط ارتفاع الجها النتاقلي) وكمية الأمطار فوق العراق. r- تحديد الموقع الجغرافي لتذبذب التساقط فوق العراق ل 
العدد الحادي والأربعون

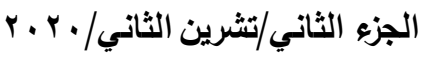

أهمية البحث :تكمن أهمية البحث من خلال دراسة حركة التيار النفاث شبه المداري(كub(Tropical Jet Stream وارتفاع تموجاته الضغطية، لما له دور كبير في حركة المنظومات الجوية التي تحته وكيفية تأثيره وتأثره بها.وما برافقه من سحب للكتل الهوائية على السطح وبالتالي ما يسببه من حالة عدم استقرار جوي وبالتالي تشكل المنخفضات الجوية المسببة لتساقط الأمطار . منهجية البحث: اعتمد الباحث على المنهج العلمي لتحليل الخرائط الطقسية الساينوبنيكية في قراءة المعطيات المناخية والخرائط الجوية اليومية (لخصائص التيار النفاث شبه المداري من حيث سرعته

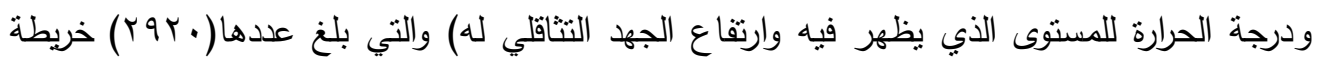
طقسية للدورتين، كما تم اعتماد الطريقة المقارنة في تحليل الخرائط الجوية السطحية والعليا، وتحليل البيانات المناخية للأمطار على المستوى الزماني والمكاني ونم الاعتماد على الأسلوب الكمي في تلهي تحديد كمية التساقط على محطات البحث لست محطات موزعة فوق المنطقة الثمالية ( الموصل وكركوك) والمنطقة الوسطى (بغداد والرطبة) والمنطقة الجنوبية (الناصرية والبصرة).كذلك استخدم الباحث الأسلوب الوصفي التحليلي من خلال وصف الحالة الجوية عند مستوى ... مكتوباسكال، والأسلوب الإحصائي والكارتوكرافي للبيانات باستخدام برنامجي ( Excel،SPSS ).وتم اختيار

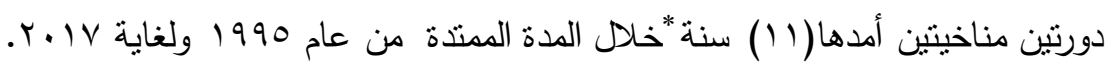

\section{حدود البحث:}

أ- تتمثل الحدود المكانية للبحث بالحدود السياسية لجمهورية العراق والذي يقع في الجزء الجنوبي الغربي لقارة آسيا محتلا القسم الشمالي الثرقي من الوطن العربي، ويعد الموقع الفلكي وفق دوائر العرض من أهم الشروط المميزة لمناخ أي منطقة ، من خلال درجة ميل الأشعة الشمسية وبالتالي كمية الطاقة التي يتلقاها الغلاف الجوي ، ومن ثم انعكاسها على درجة الحرارة الضابط الرئيس



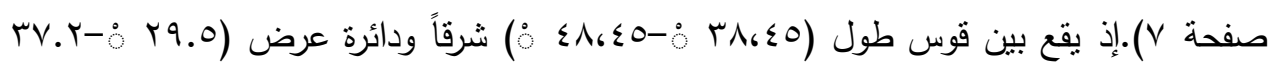

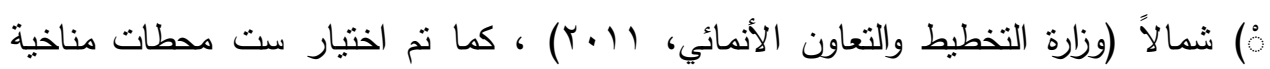

*تمثل اصغر مدة لتكرار البقع الثمسية، ضمن المدد التي حددها شواب Schwabe وهذه المدة تعادل ال سنة تقربياً الدورة المناخية الصغرى التي اقرتها منظمة الارصاد الجوية العالمية، يراجع: علي حسن موسى البقع الثمسية ودورها في التغيرات المناخية، دار الفكر، دمشق، .07 ص 61999 
العدد الحادي والأربعون

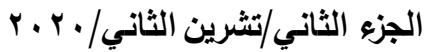

جامسعة واســـ

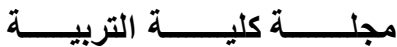

موزعة على مختلف مناطق العراق وهي الموصل وكركوك وبغداد والرطبة والناصرية والبصرة، ينظر الجدول (1) والخربطة(1)، لأجل معرفة موقع التبار النفاث

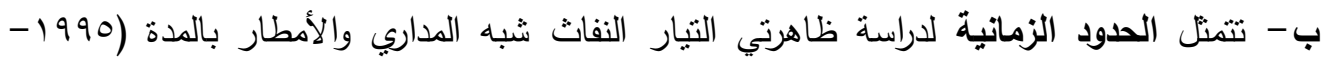

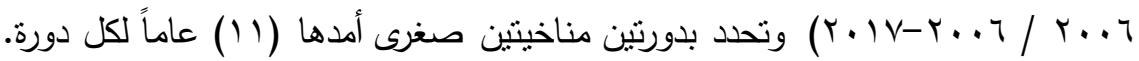
ج-الحدود الموضوعية هو دراسة وتحليل خصائص التيار النفاث شبه المداري فوق العراق وعلاقة

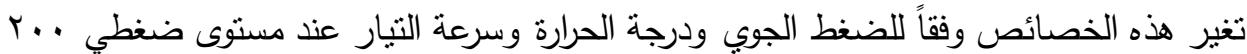
هكتوباسكال، وأثزها على أمطار العراق. جول (1): الموقع الفلكي لمحطات البحث

\begin{tabular}{|c|c|c|c|}
\hline الارتفاع/م & دائرة العرض & قوس الطول & المحطة \\
\hline TrT & ० 19,19 & $\varepsilon r, . q$ & الموصل \\
\hline וrr & $\dot{\circ} \mu_{\Delta, Y \wedge}$ & $\dot{0} \leq \varepsilon, Y \leq$ & كركوك \\
\hline$r, v$ & ¿ $r r, ı$ & $\dot{0} \leq \varepsilon, Y \leq$ & بغداد \\
\hline ג, • rז & $\dot{0} r, \cdot r$ & $\dot{0} \varepsilon, 1 V$ & الرطبة \\
\hline$r, 1$ & - $1, . k$ & $\dot{0} \leqslant \uparrow, r \mu$ & الناصرية \\
\hline$r$ & 'r, & $\leqslant V, \leqslant V$ & البصرة \\
\hline
\end{tabular}

المصدر: (الهيئة العامة للأنواء الجوية والرصد الزلزالي، أطلس مناخ العراق، ج(، بغداد، 9 . . ؟، صـ^.) خريطة (1): توزيع المحطات المناخية المختارة للبحث فوق العراق.

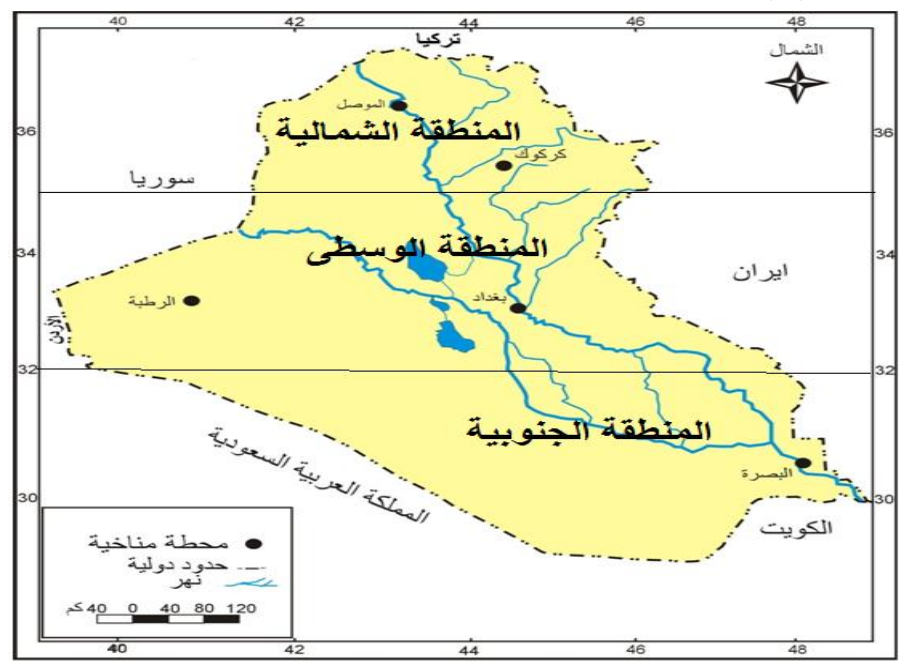

المصدر: (وزارة الموارد المائية، المديرية العامة للمساحة، خارطة العراق الإدارية، بغداد، V... . .) 
العدد الحادي والأربعون

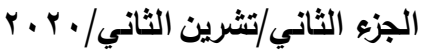

أولا: التحليل الساينويتيكي لخصائص التيار النفاث شبه المداري عن مستوى ·. . . هكتوياسكال: يمثل المستوى . . . هكتوباسكال (مليبار ) سقف التروبوسفير وأعلى طبقة التروبوبوز ،ويبلغ


الوضع القياسي ، ويختلف موقع التيار بالنسبة لدوائر العرض في الثتاء عنه في الصيف ، فيكون معدل موقعه شتاءاً في النصف الثمالي فوق دائرة (ب0 ) شمالاً إلا انه يتزحزح الى الشمال والجنوب فوق الضغط المرتفع شبه المداري مما يجعله قليل التموج بين الثمال والجنوب وهذا ما يعطيه صفة الثبات ، ويقترن ظهوره بالتقاء رياح عليا دافئة( اقل برودة) قادمة من العروض الدنيا مع رياح عليا باردة قادمة من العروض العليا (شحادة، بر9 (، صفحة • ع) ،على العكس من التيار النفاث شبه القطبي الذي يتميز بكثرة تعرجاته وتشعبه وعدم ثباته في موقعه، وان المنظومة الجوية المسيطرة على هذا المستوى هو التيار النفاث شبه المداري (Sub-Tropical Jet Stream) ، والذي يتواجد محوره عند الأطراف الثمالية لخلية هادلي (AHERNS, 2012, pp. 341-342) • بينما يكون موقع محوره في الصيف بين هب-.؛ْ شمالاً فوق شمال تركيا وجنوب البحر الأسود وحوض البحر المتوسط. وبسبب موقع العراق الفلكي فان موقع التيار النفاث شبه المداري يكون في الفصل الحار في الأقسام الثمالية منه وفوق تركيا (•؛ْ ) شمالا، اما في فصل الشتاء فان موقعه يكون فوق الأطراف الوسطى والثمالية من شبه الجزيرة العربية.ووفق ما سبق تسود الحركات الرأسية والأفقية للتيار النفاث شبه المداري مما يؤثر على حركة الأمواج العليا التي تولد المرتقعات السطحية ويقل تكرار المنخفضات الجوية الجبهوية وخاصة في فصل الصيف وذلك بسبب التسخين الاديباتيكي مع هبوط الهواء وتتاقص الرطوبة النسبية، بينما في فصل الشتاء يتزحزح التيار شبه المداري نحو الجنوب من العراق مما يسمح باقتراب التيار شبه القطبي مما يؤدي الى زيادة تكرار المنخفضات الجوية المرافقة له وبالتالي زيادة كمية الأمطار المتساقطة. تظهر علاقة قوية بين محور التيار النفاث شبه المداري ودرجات الحرارة العليا في الغلاف الجوي لهات بين المناطق المدارية والقطبية ، فالجانب الجنوبي من محور التيار النفاث يكون أدفء من الجانب

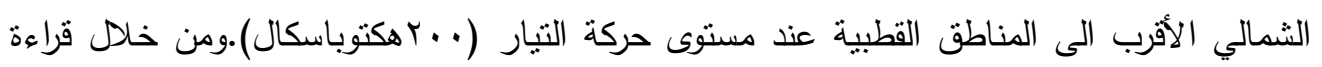

وتحليل الخرائط الطقسية للمعدل اليومي لدرجات الحرارة لهذا المستوى تبين ان المعدل السنوي بلغ (00) مُ في الدورة الأولى و(000) في الدورة الثانية فوق مناطق العراق للفصل البارد(كانون الثاني)




العدد الحادي والأريعون

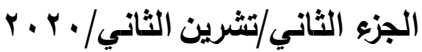

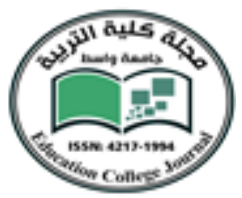

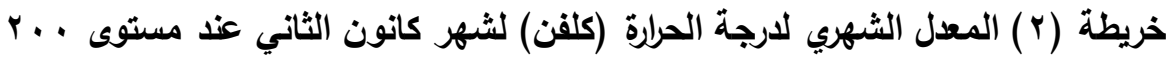
هكتوياسكال لسنة 999 الداونه (الدورة الأولى).



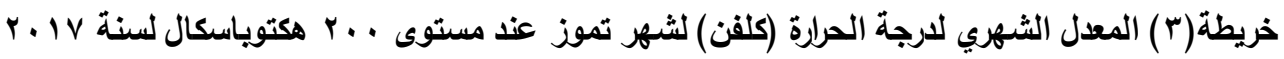
(الاورة الثانية)

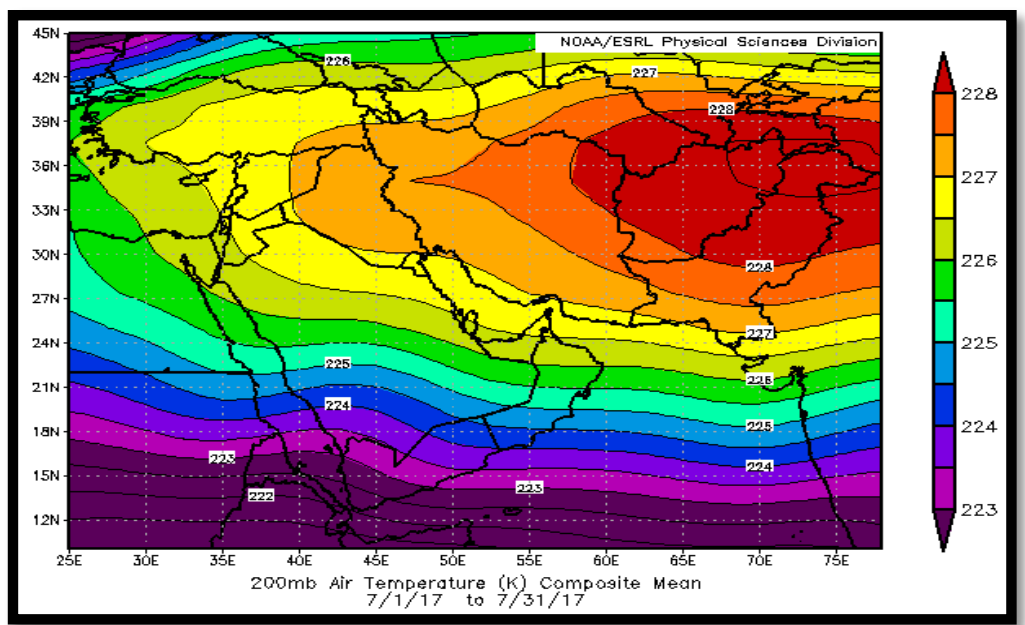

المصدر: (https://www.esrl.noaa.gov/psd/cgi-bin/data/composites/comp.day) 
العدد الحادي والأربعون

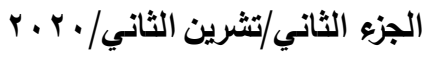

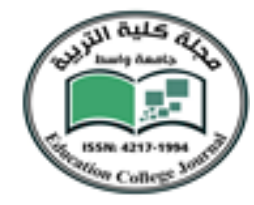

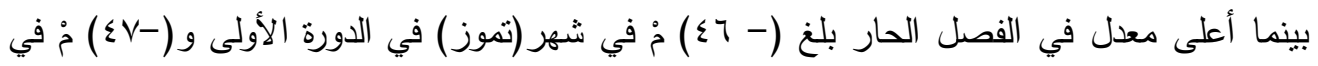

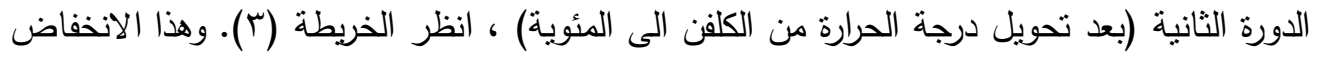

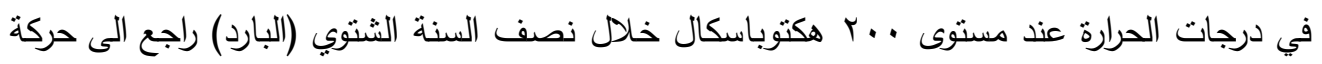

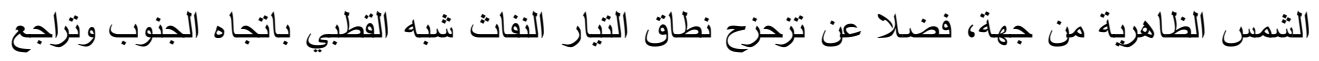
التيار النفاث شبه المداري نحو الجنوب أيضاً. مما أثر بنللك على جميع الأنظمة الجوية المحيطة



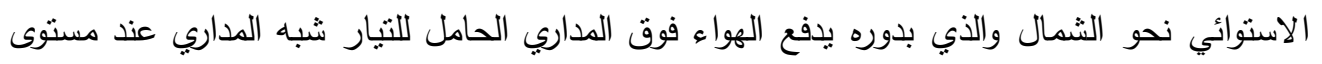

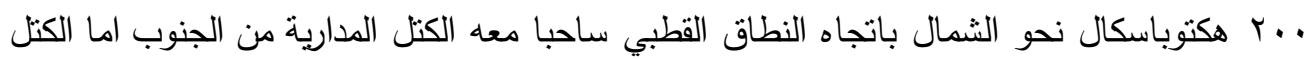

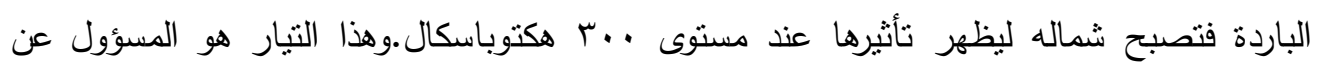

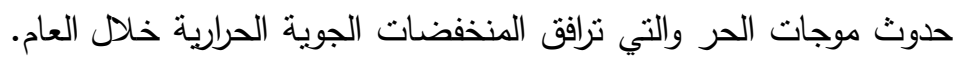

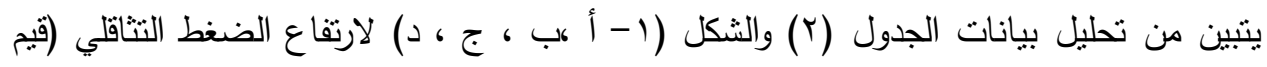

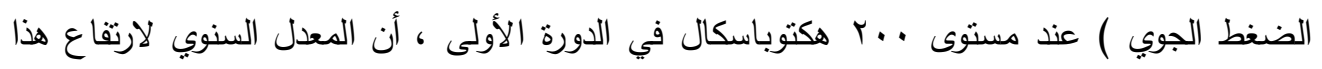

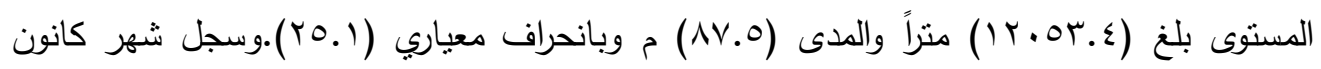

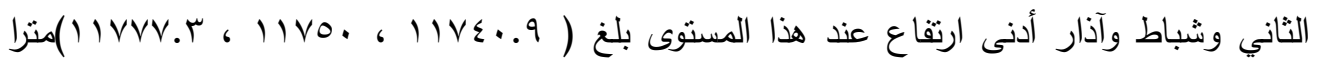



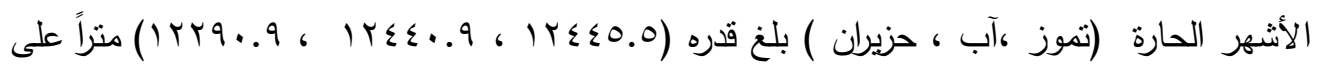



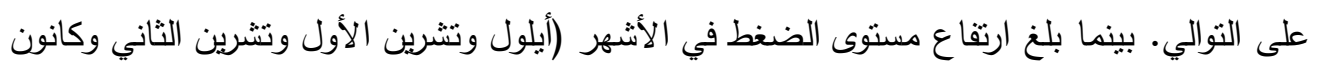

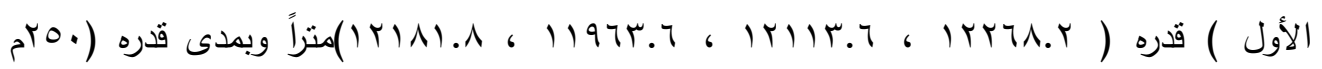

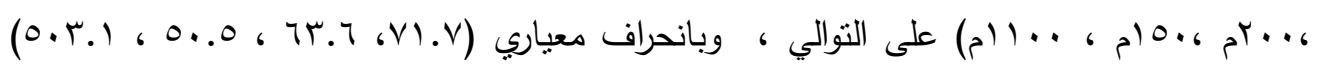

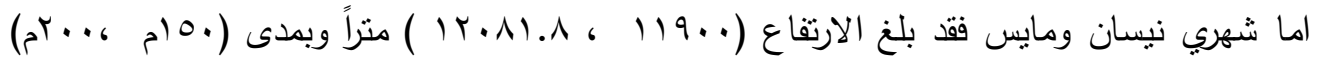

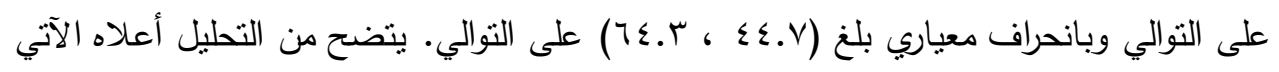


العدد الحادي والأربعون

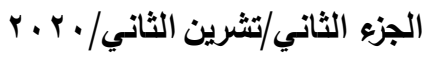

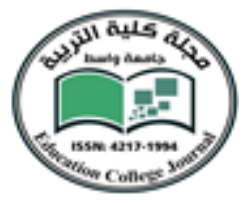

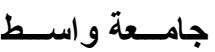



\begin{tabular}{|c|c|c|c|c|c|c|c|c|c|c|c|c|c|}
\hline & & & & & & 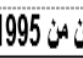 & & 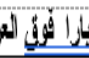 & $=2 v$ & 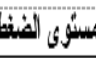 & & & \\
\hline & & & & & & 05 & 301 & $i$ & 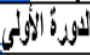 & & & & \\
\hline له & أب & ت نوز & Sزيرن & هايبن & نبسلن & أل & ئباكا & Sأتون & كالمن المله & تشزين الثاني & تنزيزين الألهل & ألملل & لسنة \\
\hline 12031 & 12400 & 12500 & 12300 & 12100 & 11800 & 11700 & 11750 & 11700 & 11800 & 11900 & 12100 & 12250 & $996 / 1995$ \\
\hline 12013 & 12400 & 12450 & 12200 & 12050 & 11850 & 11700 & 11700 & 11750 & 12850 & 12000 & 12250 & 12200 & 7719996 \\
\hline 12025 & 12400 & 12250 & 12350 & 12050 & 11950 & 11750 & 11750 & 11700 & 12850 & 11900 & 12050 & 12250 & $88 / 1997$ \\
\hline 12069 & 12450 & 12500 & 12250 & 12100 & 11900 & 11750 & 11800 & 11800 & 12800 & 12050 & 12200 & 12300 & 999/1998 \\
\hline 12069 & 12500 & 12500 & 12350 & 12050 & 11900 & 11800 & 11750 & 11700 & 11950 & 12000 & 12100 & 12300 & $0 / 1999$ \\
\hline 12100 & 12500 & 12500 & 12300 & 12200 & 11950 & 11800 & 11750 & 11800 & 11800 & 11950 & 12050 & 12350 & 112000 \\
\hline 12063 & 12250 & 12400 & 12300 & 12200 & 11900 & 11850 & 11850 & 11750 & 12750 & 11950 & 12100 & 12300 & 2212001 \\
\hline 12044 & 12500 & 12450 & 12250 & 12050 & 11900 & 11700 & 11700 & 11800 & 11750 & 12000 & 12050 & 12100 & $3 / 2002$ \\
\hline 12050 & 12450 & 12400 & 12300 & 12050 & 11900 & 11900 & 11750 & 11650 & 11800 & 12000 & 12100 & 12250 & 442003 \\
\hline 12050 & 12500 & 12450 & 12250 & 12000 & 11950 & 11800 & 11700 & 11750 & 11800 & 11900 & 12150 & 12350 & $2005 / 2004$ \\
\hline 12075 & 12500 & 12500 & 12350 & 12050 & 11900 & 11800 & 11750 & 11750 & 11850 & 11950 & 12100 & 12300 & $2006 / 2005$ \\
\hline 12053.4 & 12440.9 & 12445.5 & 12290.9 & 12081.8 & 11900.0 & 11777.3 & 11750.0 & 11740.9 & 12181.8 & 11963.6 & 12113.6 & 12268.2 & المئزبط \\
\hline 25.1 & 76.9 & 75.7 & 49.1 & 64.3 & 44.7 & 64.7 & 44.7 & 49.1 & 503.1 & 50.5 & 63.6 & 71.7 & 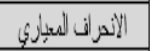 \\
\hline 87.5 & 250 & 250 & 150 & 200 & 150 & 200 & 150 & 200 & 1100 & 150 & 200 & 250 & لـ \\
\hline & & & & & & 019 & 0710 & .1 & $i$ & & & & \\
\hline له & أب & ت & دنيرن & هابين & نبسنان & لit & ئبة & 2 كائمن & كالثمن الأل & تلثنين الثاني & تلنيزين الألفل & ألبله & لسة \\
\hline 12069 & 12500 & 12450 & 12300 & 12100 & 11850 & 11800 & 11750 & 11800 & 11850 & 11900 & 12050 & 12350 & $07 / 2006$ \\
\hline 12100 & 12500 & 12550 & 12300 & 12000 & 12000 & 11900 & 11800 & 11750 & 11850 & 11950 & 12100 & 12400 & $2008 / 2007$ \\
\hline 12056 & 12400 & 12450 & 12400 & 12050 & 11850 & 11750 & 11750 & 11800 & 11900 & 11950 & 12100 & 12250 & $2009 / 2008$ \\
\hline 12119 & 12500 & 12550 & 12300 & 12100 & 11950 & 11900 & 11800 & 11850 & 11800 & 11950 & 12150 & 12200 & $2010 / 2009$ \\
\hline 12075 & 12500 & 12500 & 12300 & 12200 & 11850 & 11800 & 11750 & 11700 & 11900 & 12050 & 12100 & 12350 & $2011 / 2010$ \\
\hline 12075 & 12450 & 12500 & 12350 & 12050 & 12000 & 11800 & 11750 & 11700 & 11900 & 11850 & 12100 & 12300 & $2012 / 2011$ \\
\hline 12150 & 12500 & 12550 & 12300 & 12500 & 11900 & 11850 & 11850 & 11750 & 11850 & 11950 & 12100 & 12350 & $2013 / 2012$ \\
\hline 12100 & 12500 & 12450 & 12250 & 12050 & 11950 & 11850 & 11900 & 11850 & 11800 & 11950 & 12100 & 12300 & $2014 / 2013$ \\
\hline 12094 & 12450 & 12550 & 12350 & 12100 & 11900 & 11850 & 11750 & 11800 & 11950 & 11950 & 12100 & 12300 & $2015 / 2014$ \\
\hline 12181 & 12550 & 12600 & 12350 & 12200 & 12000 & 11950 & 11950 & 11850 & 11900 & 12050 & 12150 & 12350 & $2016 / 2015$ \\
\hline 12194 & 12550 & 12600 & 12450 & 12200 & 12050 & 11900 & 11900 & 11900 & 11950 & 12100 & 12200 & 12450 & $2017 / 2016$ \\
\hline 12110.2 & 12490.9 & 12522.7 & 12331.8 & 12140.9 & 11936.4 & 11850.0 & 11813.6 & 11795.5 & 11877.3 & 11968.2 & 12113.6 & 12327.3 & المنزبط \\
\hline 46.1 & 43.7 & 56.4 & 56.0 & 137.5 & 71.0 & 59.2 & 74.5 & 65.0 & 51.8 & 71.7 & 39.3 & 68.4 & الإندر انت للبدلبي \\
\hline 137.5 & 150 & 150 & 200 & 500 & 200 & 200 & 200 & 200 & 250 & 250 & 200 & 250 & (at) \\
\hline
\end{tabular}

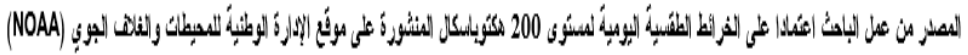


العدد الحادي والأربعون

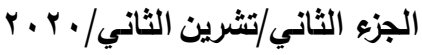



شكل (1 -أ ، ب ،ج ،د) المعل السنوي والثهري والاتجاه الخطي للقيم الضغية عند مستوى

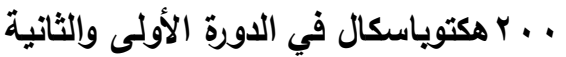

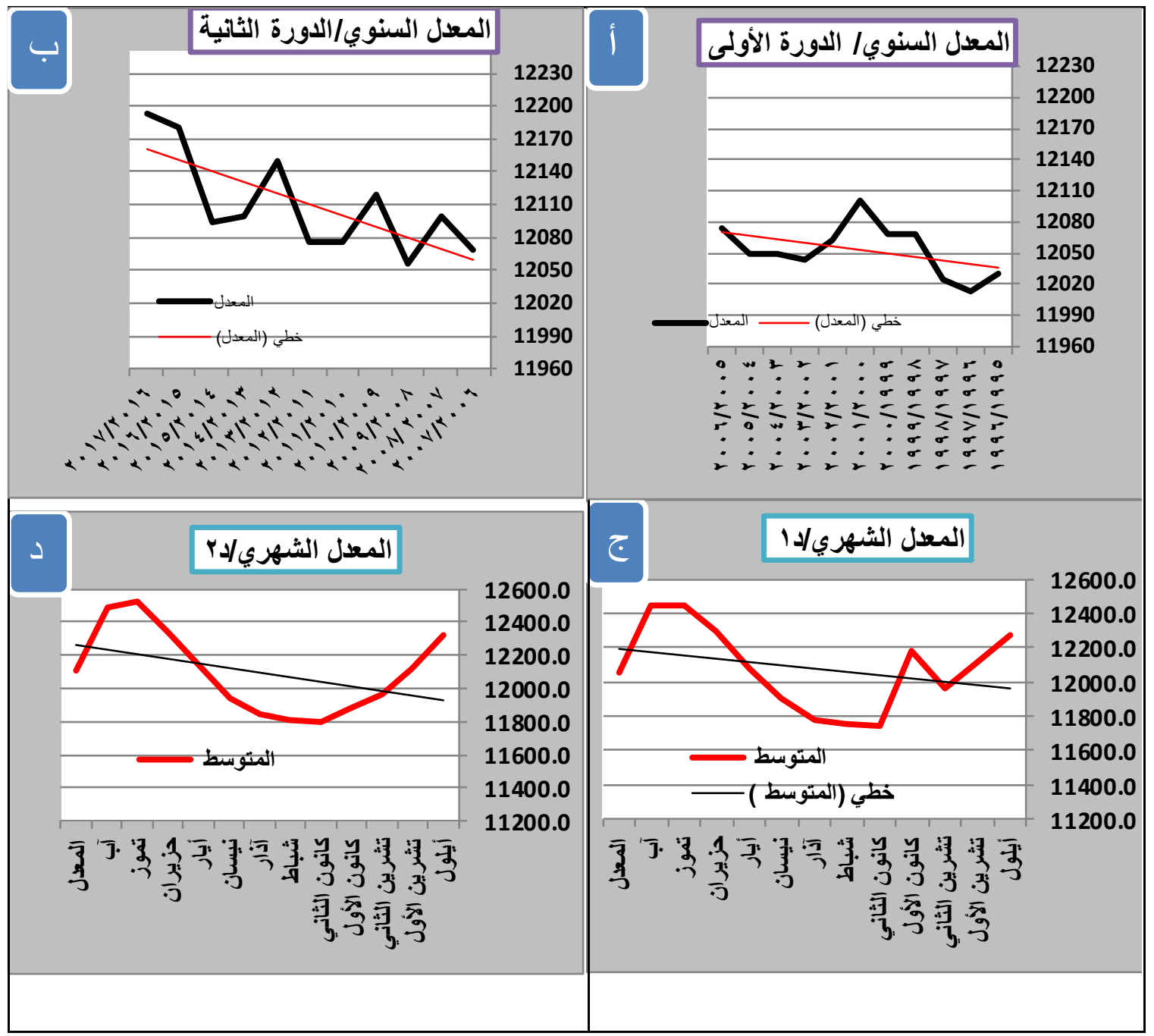


العدد الحادي والأربعون

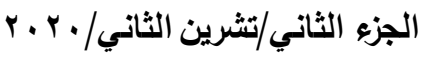

1 - وجود ارتفاع في قيمة الضغط التثاقلي عند مستوى .. . هكتوباسكال في الأشهر الحارة

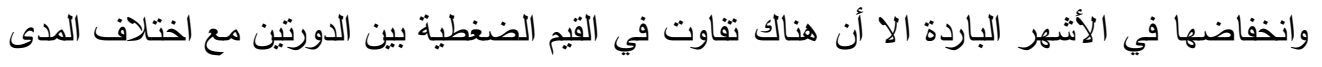

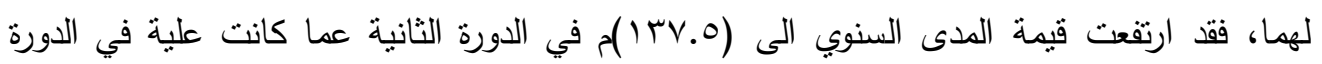

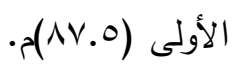

r- ارتفاع القيم الضغطية في الدورة الثانية لمعظم الثهور عدا شهري كانون الأول الذي سجل انخفاضا أما شهر تشرين الأول فكان بنفس القيمة الضغطية. r- سجل شهر تشرين الثاني وشباط ونيسان ومايس وحزيران ارتفاعا في المدى بينما سجل شهر كانون الأول وتموز وآب انخفاضا في المدى أما بقية الأشهر فكانت في القيمة ذاتها.

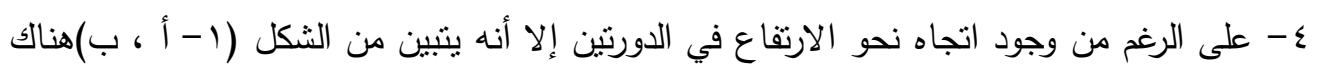
اتجاه نحو الارتفاع في معدلات قيم الضغط الجوي السنوي في الدورة الثانية أكثر مما كان عليه في

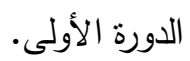

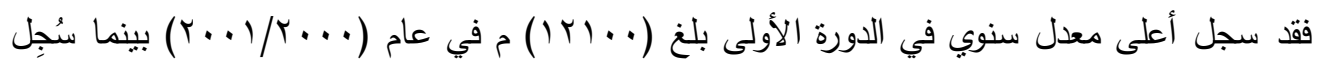

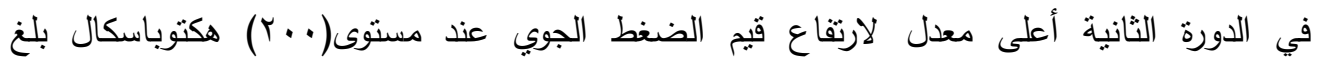

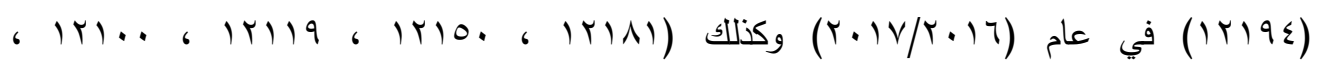

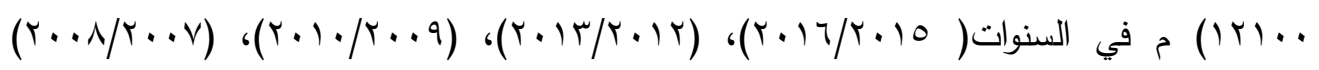

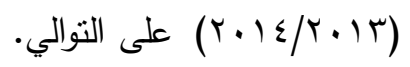

ه- هناك تباين في المعدل الثهري لارتفاع الضغط الجوي بين الدورتين ، إذ يـاحظ من الشكل

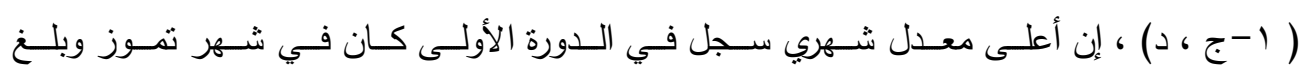

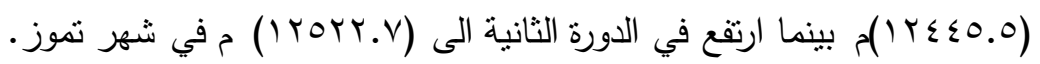
צ- سجل شهر كانون الأول في الدورة الأولى ارتفاعا في قيم ارتفاع الجهد الضغطي التثاقلي بلغ

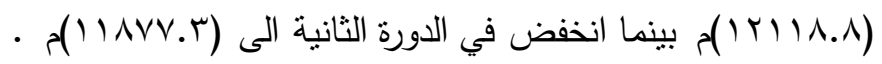

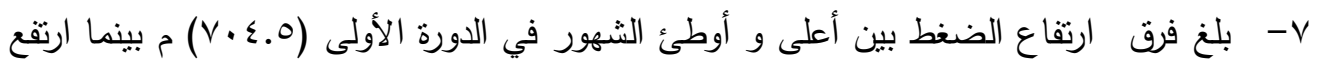

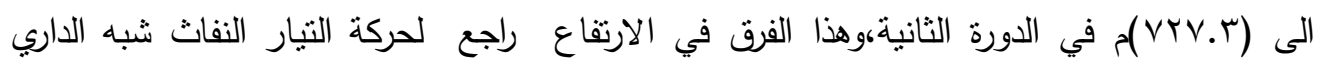
برحلته الفصلية والسنوية شمالاً وجنوباً مع حركة الثمس الظاهرية ، وبالتالي انعكاسه على طبيعة ضخ الهواء المرافق له من منابعه العليا. أما سرعة التيار النفاث شبه المداري فوق المنطقة (الثمالية والوسطى والجنوبية). أما سرعة التيار النفاث شبه المداري فوق العراق فيتضح من الجدول (r) والثكل (r-أ ، ب) الآتي: 
العدد الحادي والأربعون

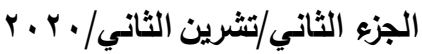

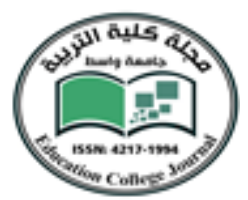

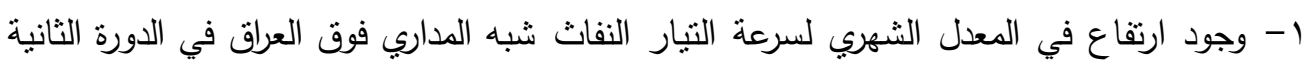

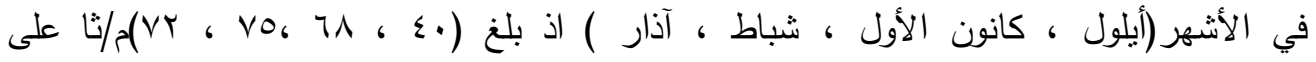

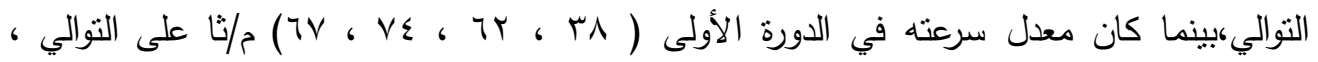

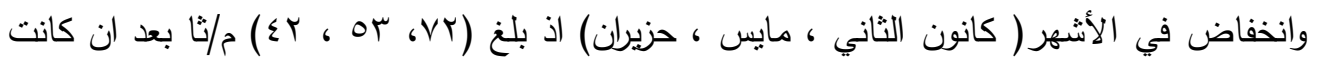

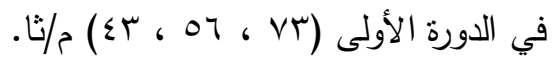

r- بلغ أقصى معدل لسرعة التيار النفاث شبه المداري في الدورة الأولى (†^م/ثاً) فوق المنطقة



جدول (Y) معدل سرعة الرياح (م/ ثا)لمستوى . . . هكتوياسكال فوق مناطق العرلق للاورة

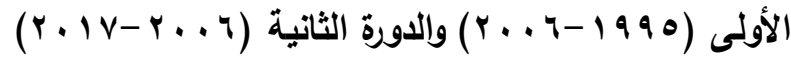

\begin{tabular}{|c|c|c|c|c|c|c|c|c|c|}
\hline \multicolumn{8}{|c|}{ الدورة الثانية } & \multicolumn{2}{|c|}{ الدورة الأولى } \\
\hline المعدل & الثمالية & الوسطى & الجنوبية & الثهارة & المعدل & الشمالية & الوسطى & الجنوبية & الثهرنة \\
\hline 40 & 46 & 41 & 33 & أيلول & 38 & 43 & 40 & 32 & أيلول \\
\hline 50 & 49 & 50 & 50 & تثرين & 50 & 50 & 51 & 48 & تثرين \\
\hline 59 & 57 & 60 & 61 & تثرينr & 59 & 57 & 60 & 59 & تشرينr \\
\hline 68 & 64 & 69 & 71 & كانون & 62 & 57 & 63 & 66 & كانونا \\
\hline 72 & 67 & 74 & 76 & كانونr & 73 & 66 & 75 & 77 & كانون \\
\hline 75 & 73 & 77 & 74 & شباط & 74 & 68 & 76 & 78 & شباط \\
\hline 72 & 69 & 74 & 73 & آذار & 67 & 60 & 69 & 73 & آذار \\
\hline 61 & 59 & 62 & 63 & نيسان & 61 & 55 & 62 & 65 & نيسان \\
\hline 53 & 51 & 54 & 54 & مايس & 56 & 54 & 58 & 55 & مايس \\
\hline 42 & 45 & 42 & 38 & حزيران & 43 & 48 & 45 & 36 & حزيران \\
\hline 24 & 35 & 23 & 15 & تموز & 27 & 36 & 27 & 17 & تموز \\
\hline 27 & 35 & 28 & 19 & آب & 25 & 34 & 25 & 17 & آب \\
\hline
\end{tabular}

المصر من عمل الباحث اعتمادا على بيانات الإدارة الوطنية للدحيطات والغلاف 
العدد الحادي والأربعون

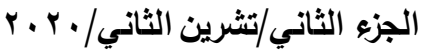



شكل (ץ -أ ، ب) معدل سرعة التيار النفاث شبه المداري فوق مناطق العرلق في الاورة الأولى والدورة الثانية
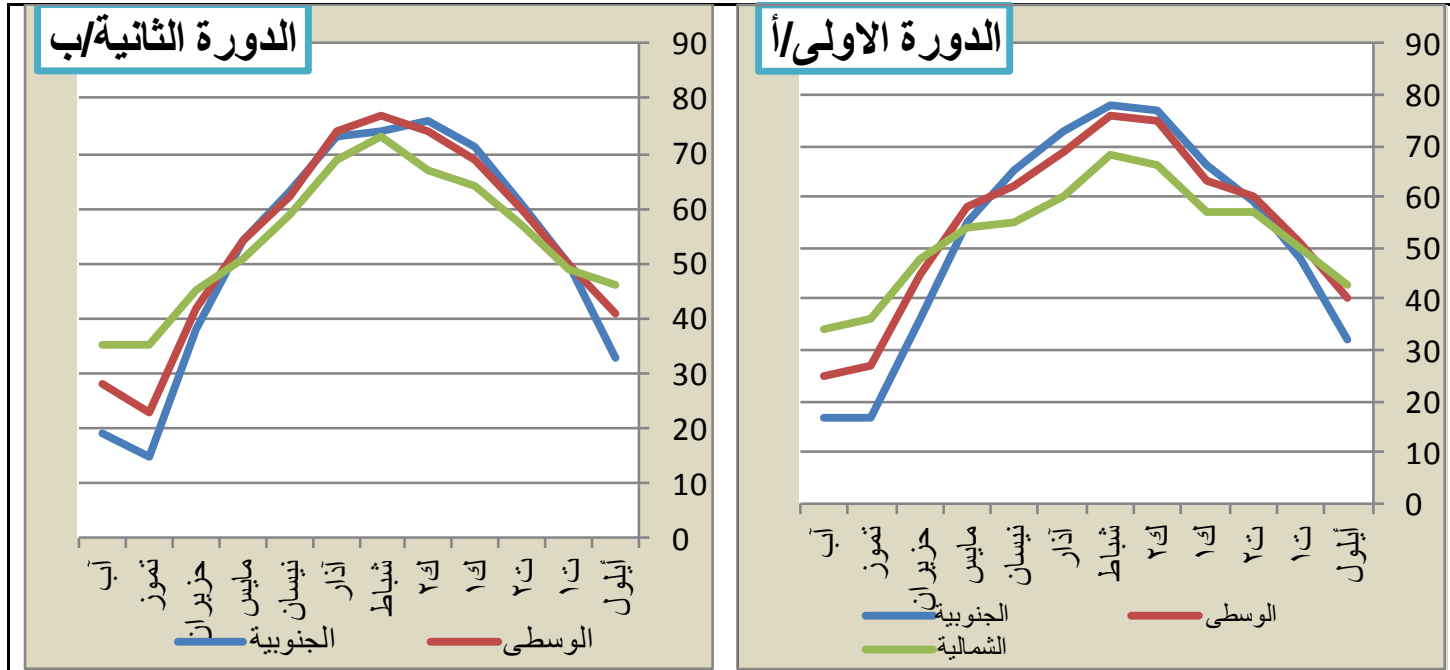

المصدر من عمل الباحث اعتمادا على الجدول (r)

شهر شباط وفي الدورة الثانية (VV) التيار النفاث الى الثمال من موقعه. - يلاحظ من الشكل (r-أ ، ب) ان المنطقة الجنوبية قد سجلت أعلى معدل لسرعة التيار النفاث في الفصل البارد في الدورة الأولى بينما سجلت المنطقة الوسطى أعلى معدل لسرعته في الدورة الثانية. ع - ارتفاع معدل سرعة التيار النفاث شبه المداري في الدورة الثانية فوق المنطقة الثمالية عما كانت

عليه في الدورة الأولى في الفصل البارد مما يدل على تغير محور التيار الى الثمال من موقعه . ه- لم يظهر التيار النفاث شبه المداري فوق العراق في شهري تموز وآب لابتعاده الى الثمال من العراق بسبب الحركة الظاهرية للشمس. ثانياً: أثر الموقع الجغرافي في تذبذب الأمطار: يتأثز العراق خلال السنة بتكرار التيار النفاث شبه المداري بشكل منباين زمانياً ومكانياً مما

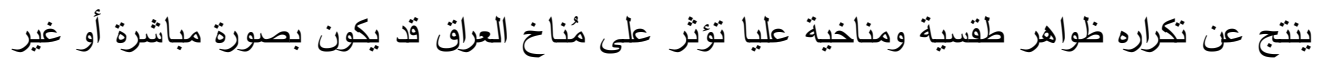
مباشرة، كما قد يكون له علاقة بالظواهر السطحية التي توجد تحته ومنها المرتفعات والمنخفضات الجوية، إذ تمثل المرتفعات والمنخفضات الجوية أحدى الظواهر المُناخية المهمة التي يتم تحديدها زمانيا ومكانيا من خلال تحليل الخرائط الطقسية اليومية، والتي تعتبر مصدر بعث للرياح كافة التي تتطلق منه مسايرة في اتجاهها لحركة عقارب الساعة في نصف الكرة الثمالي وبالعكس للمنخفضات 
العدد الحادي والأربعون

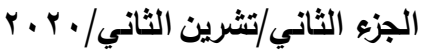

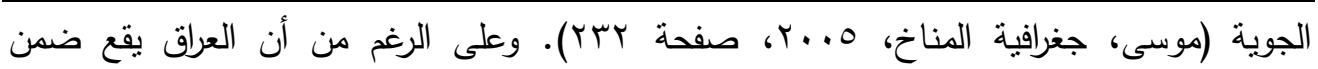



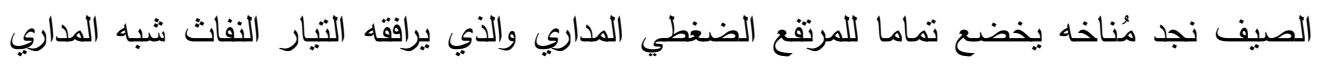
،مما يجعل الطقس ذا سماء صافية في الغالب، فضلا عن ارتفاع كمية الإشعاع الواصلة للسطح

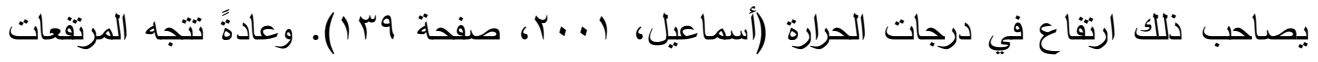

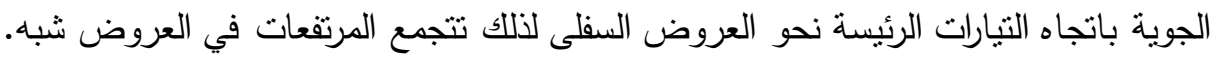

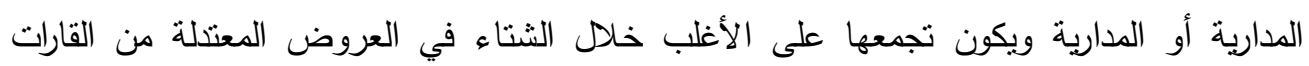

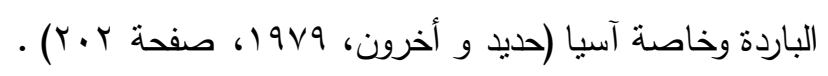
يتضح من الجدول (乏) والثكل (r) إنَّ أعلى معدل شهري لكمية الأمطار المتساقطة فوق العراق

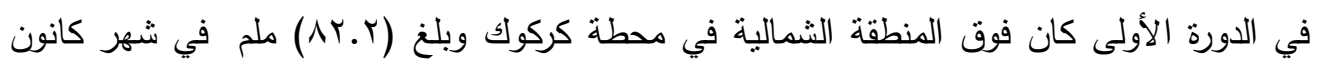

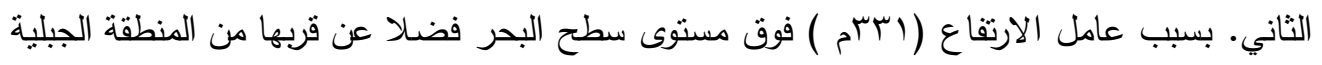

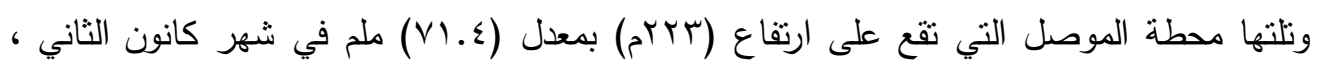

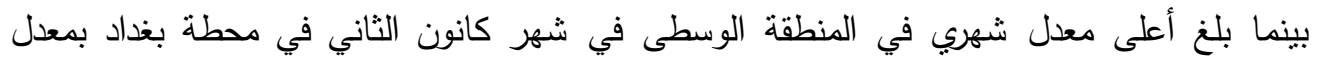

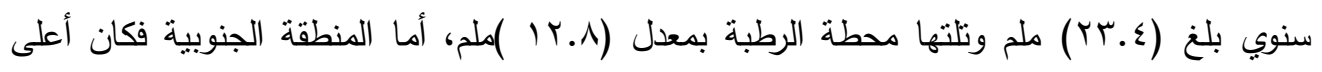

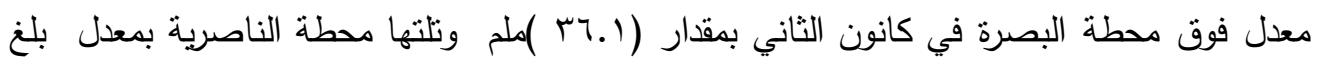

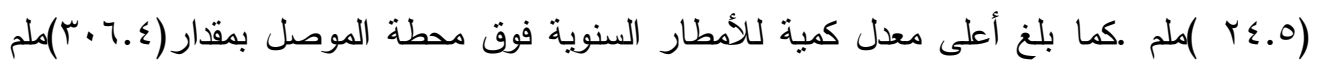

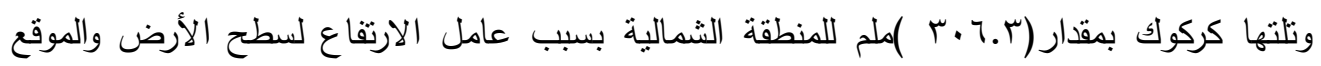

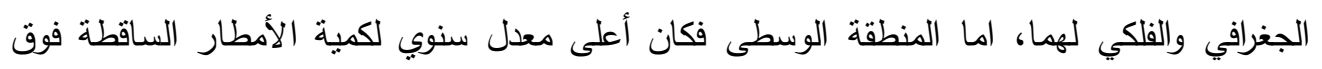




العدد الحادي والأربعون

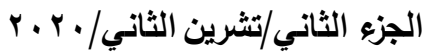

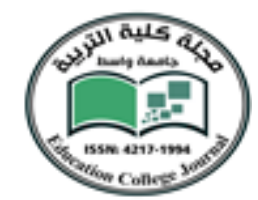

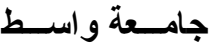

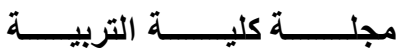

جدول (؛ ) المتوسط الثهري والسنوي والانحراف المعياري للأمطار (ملم) فوق مناطق العرلق للاورة

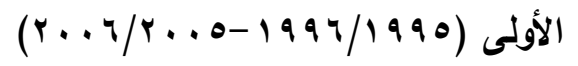

\begin{tabular}{|c|c|c|c|c|c|c|c|c|c|c|c|c|c|c|c|}
\hline معل كمية & آب & تموز & دزيران & أيار & نيسان & أذار & شباط & 2 & كاتون 1 & تشرين 2 & تشرين 1 & أيلول & المحطة & المنطقة & 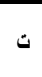 \\
\hline 306.4 & 0 & 0.5 & 0.9 & 8.7 & 33.6 & 48 & 49.6 & 71.4 & 57.1 & 28.3 & 8.1 & 0.3 & الموصل & \multirow{2}{*}{ المنطقة الثمالية - } & 1 \\
\hline 306.3 & 0 & 0.7 & 0.2 & 8.2 & 32.7 & 40.8 & 49.1 & 82.2 & 55.4 & 29 & 6.3 & 1.6 & كركوك & & 2 \\
\hline 89.1 & 0 & 0 & 0 & 1.9 & 14.3 & 13.8 & 10.3 & 23.4 & 14.1 & 9.8 & 1.5 & 0 & بذاد & \multirow{2}{*}{ المنطقة الوسطى | } & 3 \\
\hline 97.6 & 0.1 & 0.2 & 0 & 4.2 & 6.4 & 12.1 & 24.9 & 12.8 & 10.2 & 14.2 & 12.6 & 0.1 & الزطبة & & 4 \\
\hline 109.9 & 0 & 0 & 0 & 0.5 & 16.7 & 20.9 & 15.1 & 24.5 & 20.5 & 10.1 & 1.6 & 0 & الناصرية & \multirow{2}{*}{ المنطقة الجنوبية } & 5 \\
\hline 118.7 & 0 & 0 & 0 & 1.5 & 10.3 & 14.3 & 16.1 & 36.1 & 29.6 & 10.1 & 0.7 & 0 & البصرة & & 6 \\
\hline 171.3 & 0 & 0.2 & 0.2 & 4.2 & 19 & 25 & 27.5 & 41.7 & 31.1 & 16.9 & 5.1 & 0.3 & \multicolumn{3}{|c|}{ المترسط السنوي } \\
\hline 112.3 & 0 & 0.3 & 0.4 & 3.6 & 11.5 & 15.5 & 17.5 & 28.3 & 20.5 & 9.3 & 4.7 & 0.6 & \multicolumn{3}{|c|}{ الاندر انـ المعياري } \\
\hline
\end{tabular}

المصدر : من عمل الباحث اعتمادا على: (وزارة النقل والمواصلات، الهيئة العامة للأنواء الجوية

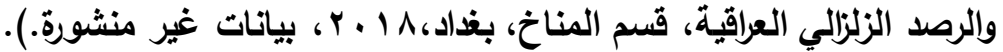

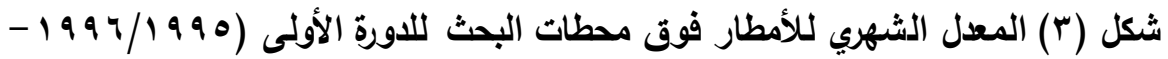

$$
(r . r / r \ldots 0
$$

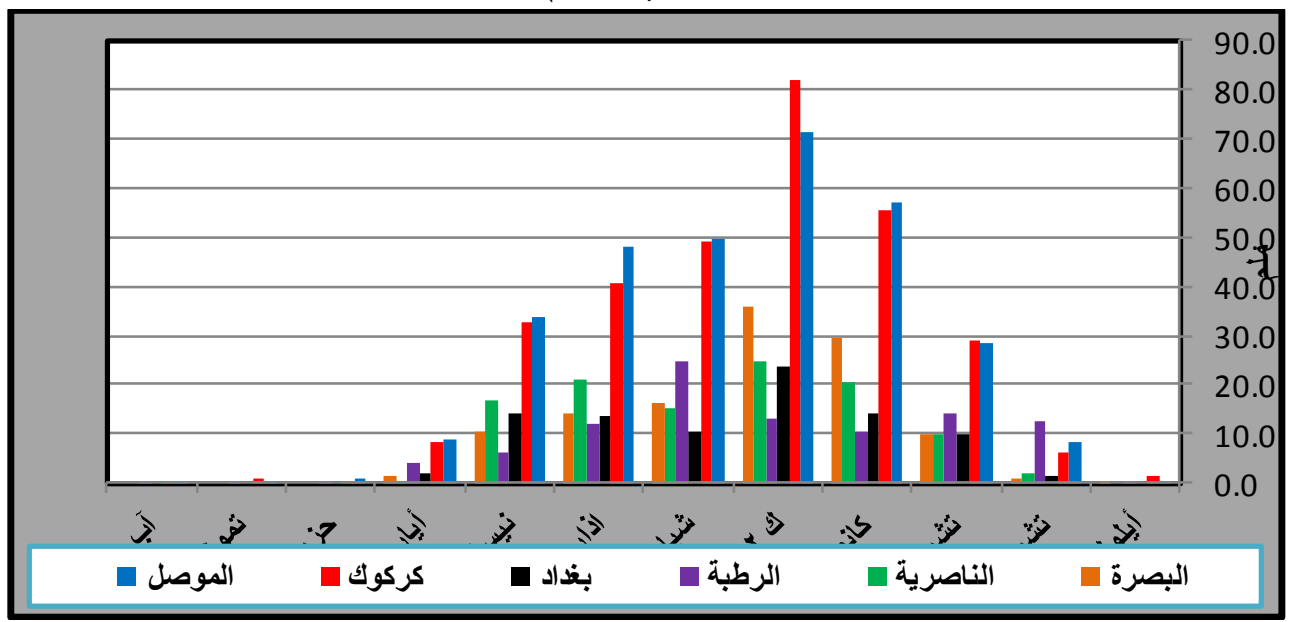

المصدر :من عمل الباحث اعتمادا على الجدول (؛) 
العدد الحادي والأربعون

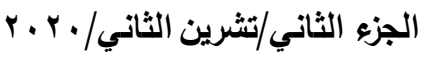

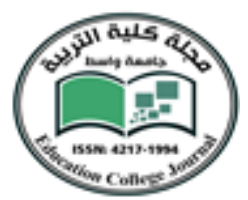

بينما سجلت المنطقة الجنوبية أعلى معدل سنوي فوق محطة البصرة بمقدار ( I.V.V) ملم ومحطة الناصرية بمعدل سنوي بلغ (9.9 • (1) ملم.وسجلت ادني قيم للانحراف المعياري في شهر آب

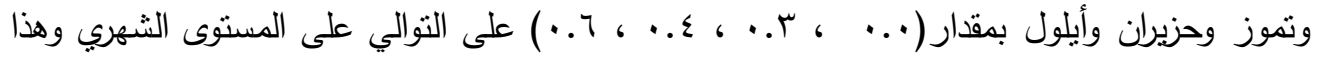
مؤشر على وجود التيار النفاث شبه المداري عند مستوى ... هكتوباسكال وما يرافقه من انبعاجات المرتفعات الجوية عند مستوى . .0 هكتوباسكال والتي تقف عائقا اما المنخفضات الجوية القادة مع الرباح الثمالية الغربية السائدة مما يؤدي الى قلة التساقط في هذه الأشهر . أما في الدورة الثانية، فيتضح من الجدول (0) والثكل (ع) أن أعلى معدل لكمية الأمطار الساقطة فوق العراق في المنطقة الشمالية كانت فوق محطة كركوك بمعدل (س.؟؛)ملم في شهر آذار وتلتها

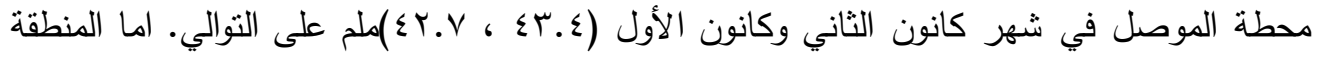

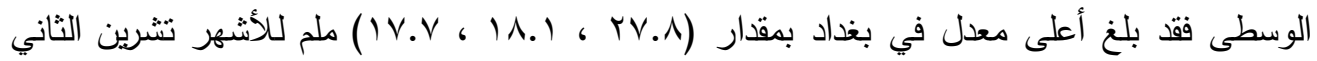
وكانون الأول وكانون الثاني على التوالي بينما ثلتها محطة الرطبة بمعل(ع . . () ملم في شهر كانون الثاني.أما أعلى معدل شهري فوق المنطقة الجنوبية فجاءت محطة الناصرية بمقدار(Y)ملم في شهر تشرين الثاني ، بينما بلغ أعلى معدل في محطة البصرة (V.9) (Vلم في شهر كانون الأول. أما المتوسط السنوي فقد سجلت محطة الموصل أعلى معدل لكمية الأمطار بلغت (1.بrم) ملم تلتها محطة كركوك بمعدل (r.r؟r)ملم وجاءت محطة بغداد بالمرتبة الثالثة بمقار (17.0 (1)ملم وفي

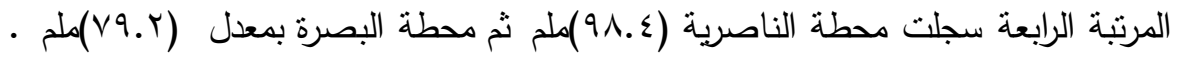
جدول (0) المتوسط الثهري والسنوي والانحراف المعياري للأمطار (ملم )فوق مناطق العرلق

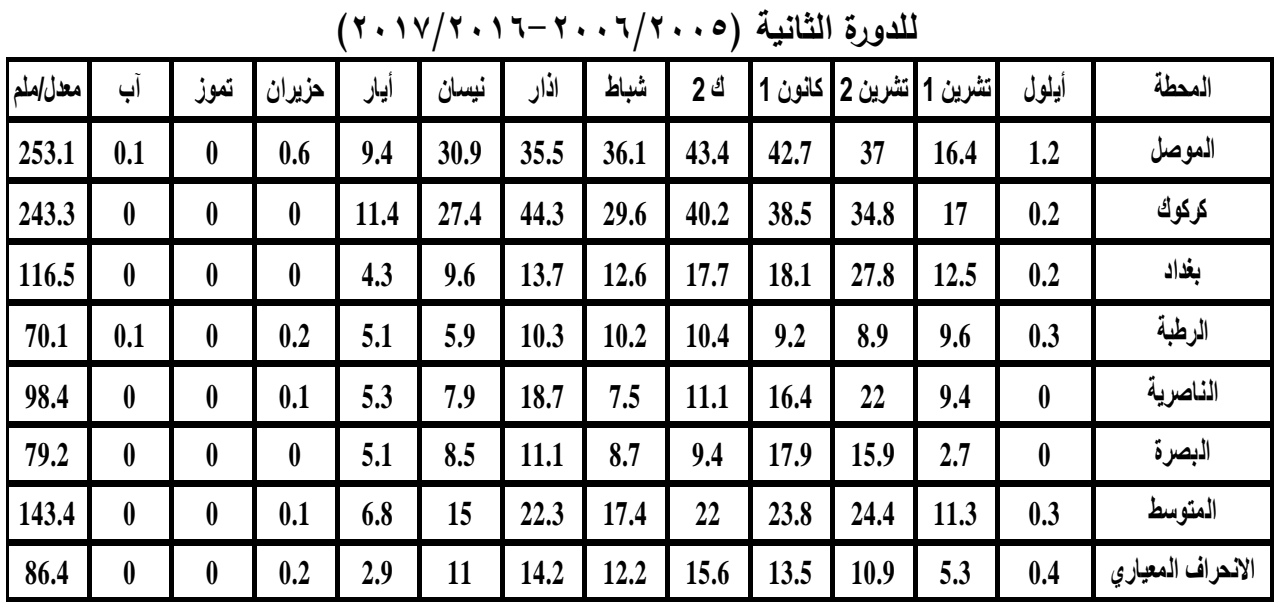

المصدر : من عمل الباحث اعتمادا على: (وزارة النقل والمواصلات، الهيئة العامة للأنواء الجوية والرصد الزلزالي




العدد الحادي والأربعون

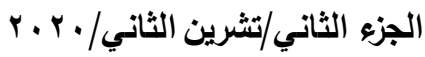



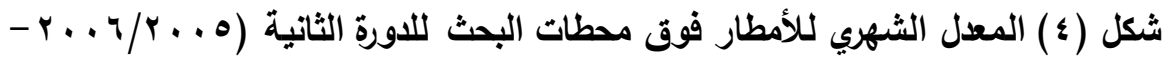

$(r+1 V / r+14$

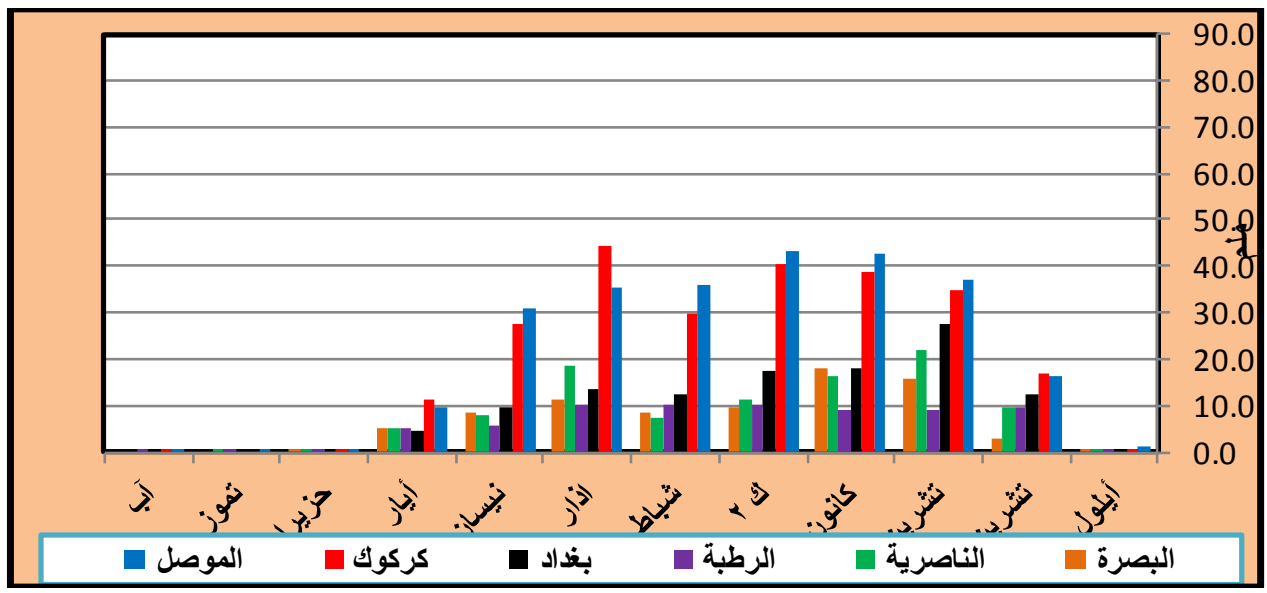

المصدر :من عمل الباحث اعتمادا على الجدول (ه)

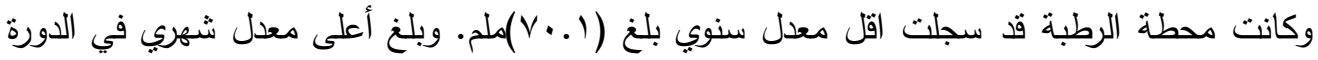

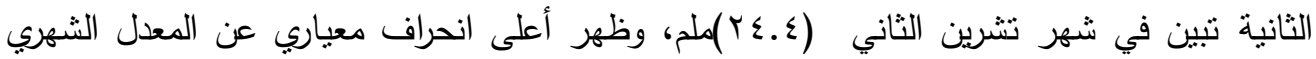

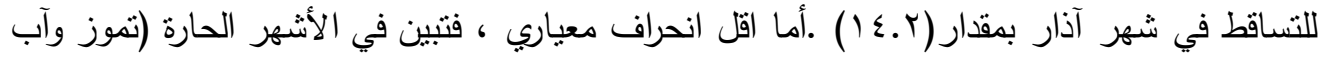

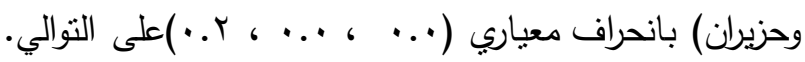

ثالثاً: تحديد العلاقة بين معل كمية الأمطار وقيم الضغط الجوي عند مستوى . . ب هكتوياسكال فوق العرلق

يتضح من الجدولين (T و V) إن قيمة معامل الارتباط (Pearson) في الدورة الأولى بين قيم الضغط الجوي عند مستوى .. . هكتوباسكال ومعدل كمية الأمطار السنوية كانت(سالبة) عكسية بمعنى انه

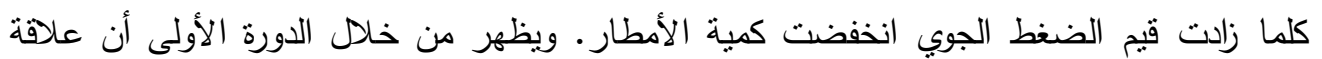

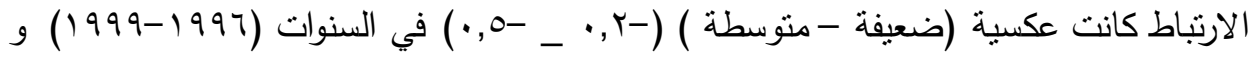

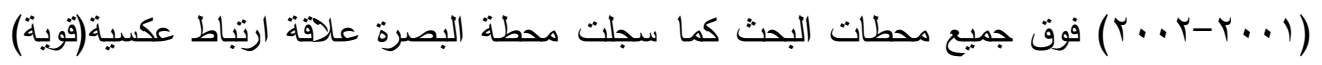



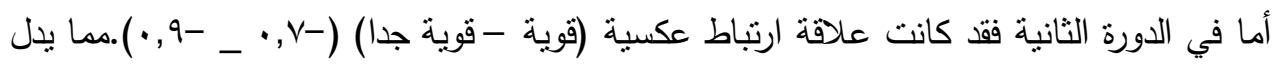
على ظهور التيار النفاث شبه المداري وسيطرته على أجواء العراق والذي بدورة يقوم بسحب النه 
العدد الحادي والأربعون

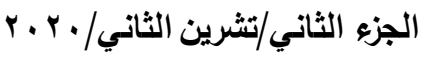

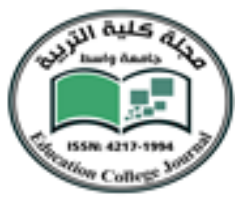

جامــعة و اســط

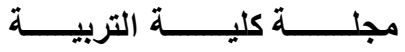

المرتفعات الجوية والكتل الهوائية الدافئة مما يؤدي الى قلة تكرار المنخفضات الجوية مما يؤدي الى انخفاض معدل التساقط للأمطار فوق العراق خلال الفصل البارد . إن قوة التيار النفاث شبه المداري وتكراره مع ظهوره في الخرائط الجوية لمستوى ... هكتوباسكال يثير الى انه يقوم بسحب الكتل المدارية البحرية الرطبة والجافة وحسب طبيعة محوره وما يرافقه من انبعاجات عليا تقف.

جلول (7 ) علاقة الارتباط (بيرسون) السنوية بين معدل كمية الأمطار وارتفاع مستوى الضغط

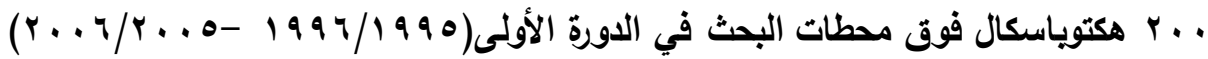

\begin{tabular}{|c|c|c|c|c|c|c|}
\hline البصرة & الناصرية & الرطبة & بغداد & كركوك & الموصل & السنة/المحطة \\
\hline-0.8 & -0.9 & -0.8 & -0.9 & -0.9 & -0.9 & $1996 / 1995$ \\
\hline-0.2 & -0.4 & -0.5 & -0.4 & -0.4 & -0.4 & $1997 / 1996$ \\
\hline-0.2 & -0.3 & -0.5 & -0.4 & -0.4 & -0.3 & $1998 / 1997$ \\
\hline-0.2 & -0.4 & -0.5 & -0.5 & -0.4 & -0.4 & $1999 / 1998$ \\
\hline-0.8 & -0.9 & -0.8 & -0.9 & -0.9 & -0.9 & $2000 / 1999$ \\
\hline-0.8 & -0.9 & -0.9 & -0.8 & -0.9 & -0.9 & $2001 / 2000$ \\
\hline-0.2 & -0.4 & -0.5 & -0.5 & -0.4 & -0.4 & $2002 / 2001$ \\
\hline-0.7 & -0.8 & -0.8 & -0.8 & -0.8 & -0.9 & $2003 / 2002$ \\
\hline-0.9 & -0.9 & -0.8 & -0.9 & -0.9 & -0.9 & $2004 / 2003$ \\
\hline-0.8 & -0.9 & -0.8 & -0.8 & -0.9 & -0.9 & $2005 / 2004$ \\
\hline-0.8 & -0.9 & -0.8 & -0.9 & -0.9 & -0.9 & $2006 / 2005$ \\
\hline-0.6 & -0.7 & -0.7 & -0.7 & -0.7 & -0.7 & المتوسط \\
\hline
\end{tabular}

المصدر : من عمل الباحث اعتمادا على الجدولين (r و \& )

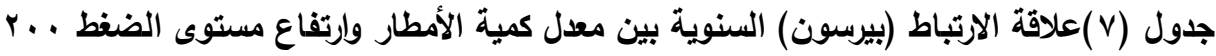

\begin{tabular}{|c|c|c|c|c|c|c|}
\hline البصرة & الناصرية & الرطبة & بغداد & كركوك & الموصل & السنة \\
\hline-0.8 & -0.8 & -0.9 & -0.7 & -0.9 & -0.9 & $2007 / 2006$ \\
\hline-0.8 & -0.8 & -0.9 & -0.8 & -0.9 & -0.9 & $2007 / 2008$ \\
\hline-0.8 & -0.8 & -0.9 & -0.7 & -0.9 & -0.9 & $2009 / 2008$ \\
\hline-0.8 & -0.7 & -0.9 & -0.8 & -0.9 & -0.9 & $2010 / 2009$ \\
\hline-0.7 & -0.7 & -0.9 & -0.7 & -0.9 & -0.9 & $2011 / 2010$ \\
\hline-0.8 & -0.8 & -0.9 & -0.8 & -0.9 & -0.9 & $2012 / 2011$ \\
\hline-0.8 & -0.8 & -0.9 & -0.8 & -0.9 & -0.9 & $2013 / 2012$ \\
\hline-0.9 & -0.8 & -0.9 & -0.8 & -0.9 & -0.9 & $2014 / 2013$ \\
\hline-0.8 & -0.7 & -0.9 & -0.8 & -0.9 & -0.9 & $2015 / 2014$ \\
\hline-0.8 & -0.8 & -0.9 & -0.8 & -0.9 & -0.9 & $2016 / 2015$ \\
\hline-0.8 & -0.8 & -0.9 & -0.8 & -0.9 & -0.9 & $2017 / 2016$ \\
\hline-0.8 & -0.8 & -0.9 & -0.8 & -0.9 & -0.9 & المتوسط \\
\hline
\end{tabular}



المصدر : من عمل الباحث اعتمادا على الجدولين (r و ه) 
العدد الحادي والأربعون

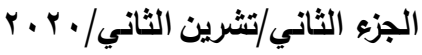

حاجزاً أمام تقدم المنخفضات الجوية القادة من الغرب والثمال الغربي من العراق، اذا يظهر تأثير المنخفضات الحرارية منل منخفض البحر الأحمر والمنخفض السوداني ومنخفض الهند الموسمي فضلا عن زيادة تكرار المرتفعات الجوية الجافة في الفصول الانتقالية.

نتائج البحث:

ا - إن للتغير المناخي أثزّ في تغير المنظومات الضغطية الجوية العليا بما فيها التيار النفاث شبه المداري والمنظومات الجوية السطحية منل المرتفعات والمنخفضات . r - هناك تغير في خصائص التيار النفاث شبه المداري من حيث درجة حرارة المستوى الذي يتحرك فيه وسرعتة وقيم الجهذ التثاقلي فوق العراق بين الدورة الأولى والثانية. r- وجود ارتفاع في قيم الضغط الثناقلي عند مستوى .. مكتوباسكال الثهري، واتجاه نحو الارتفاع في معدلات قيم الضغط الجوي السنوي في الدورة الثانية أكثر مما كان عليه في الدورة

ع - وجود ارتفاع في المعدل الثهري لسرعة التيار النفاث شبه المداري فوق العراق في الدورة الثانية وتغير في حركة وشكل الأمواج الهوائية الحاملة له وما نتج عن حركة التيار النفاث من انبعاجات واخاديد هوائية والتي بدورها أثرت على نوع المنظومات المسيطرة على مناخ العراق من مرتفعات جوية ومنذفضات حرارية مع قلة تكرار المنخفضات الجوية الجبهوية التي أدت بدورها الى قلة أو تذبذب أمطار العراق في السنوات الأخيرة من مدة البحث. ه- ظهور علاقة ارتباط عكسية قوية جدا بين ارتفاع قيم الضغط الجوي عند مستوى .. هكتوباسكال وكمية التساقط فوق مناطق العراق في الدورة الثانية ، كان سببه تغير وتزحزح التيار النفاث خلال حركته فوق العراق الى الثمال من موقعه. צ - إن تغير الخصائص الطقسية والمناخية للتيار النفاث شبه المداري من حيث الحرارة والضغط الجوي وسرعته ،أدت الى تغير المنظومات الضغطية التي تحته وهذا بدورة أدى الى سبطرة المرتفعات الجوية ، مما ادى الى انخفاض تكرار المنخفضات الجبهوية المسببة للأمطار . 
العدد الحادي والأربعون

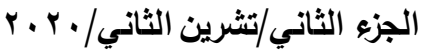

V - ظهور التيار النفاث شبه المداري وسيطرته على أجواء العراق معظم أيام السنة والذي بدورة يقوم بسحب المرتفعات الجوية والكتل الهوائية الدافئة ،مما يؤدي الى قلة تكرار المنخفضات الجوية وخاصة المنخفضات الجبهوية المرافقة للتيار شبه القطبي والى انخفاض معدل التساقط للأمطار

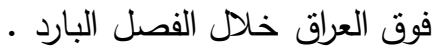
1 - انخفاض معدل كمية الامطار المتساقطة في الدورة الثانية عما كان علية في الدورة الأولى.

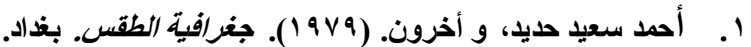



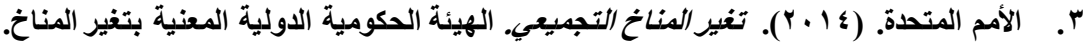

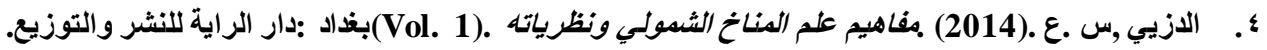

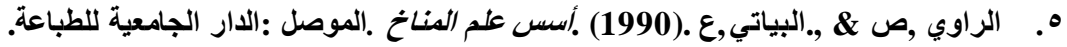

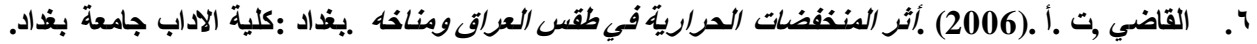

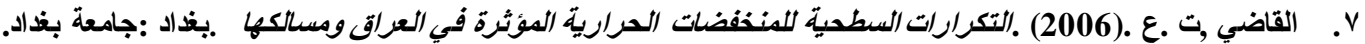

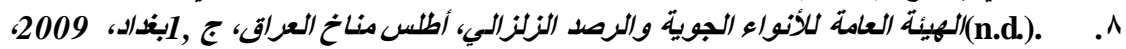

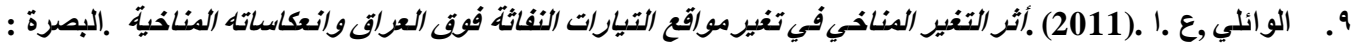

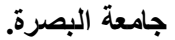

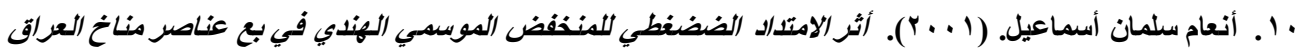

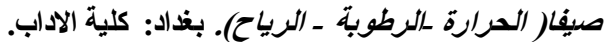

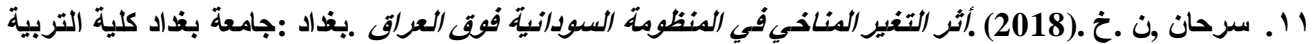
لانبنات.

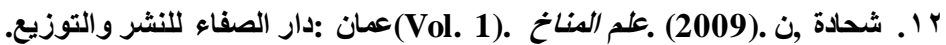



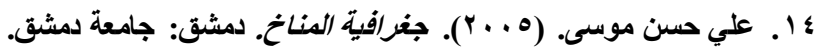

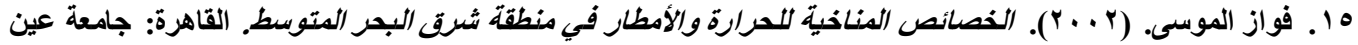
شمس. 17 . ليث محمود الزنكنه. (79 9 (1)). موقع التيار النفاث وأثرة في منذفضات وأمطار العراق. بذاد: جامعة .

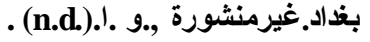

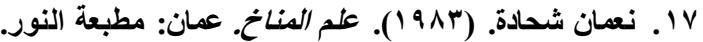


و وتكنلوجيا المعلومات.

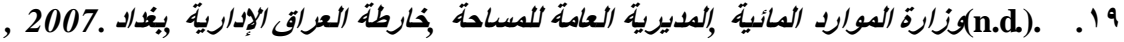

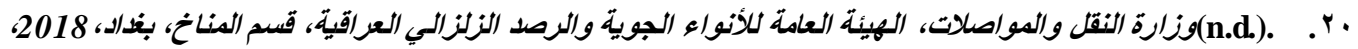
بيانات غير منشورة . مزئ 
العدد الحادي والأربعون

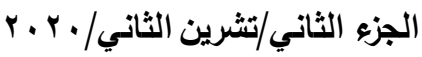

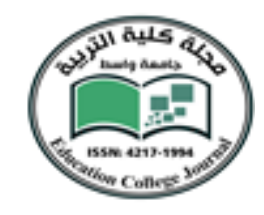

21. AHERNS, C. D. (2012). Metrology to day:Antroduction to weather climate and the Environment. USA: modes to junior collge california.

22. (n.d.). https://www.esrl.noaa.gov/psd/cgi-bin/data/composites/comp.day.

23. T.Hardy, J. (2003). climatechange. washington, USA: university/BELINGHAM 